УДК: 332.143

ШЕВЦОВ ВЛАДИМИР ВИКТОРОВИЧ

д.э.н., профессор Кубанский государственный аграрный университет им. И.Т.Трубилина, г. Краснодар, e-mail: denshevtsov0@ya.ru

КАРПЕНКО ГАЛИНА ГРИГОРЬЕВНА

д.э.н., профессор Кубанский государственный аграрный университет им. И.Т.Т уубилина, г. Краснодар, e-mail: denshevtsov0@ya.ru

\title{
ХАКЕРСКИЕ ПРАКТИКИ В АГРОБИЗНЕСЕ
}

Аннотауия. Џель статьн: на основе анализа показателей функиионирования АПК Крас-

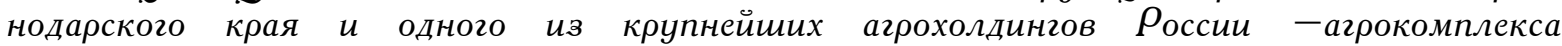
«Выселковский», а также практики эффективного использования современных кониепиий маркетинга и менеджмента сформулировать направления совершенствования маркетинга и менеджмента в современных российских агропредприятиях, реализация которых способна существенно повысить устойчивость российского агрокомплекса в условиях санкиионного противостояния и импортозамещения. Методологическую базу работы составляют кониепиии Agile-маркетинга и менеджмента, маркетинг-менеджмента, системный, синергетический и прогностический подходы. В работе используются общетеоретические (анализ, синтез, аналогия, сравнение и сопоставление, обобщение, типизация) и общенаучные методы. Результаты. Обосновывается целесообразность применения хакерских практик в агробизнесе, вытекающих из современных кониепиий маркетинга и менеджмента, в основе которых Agile-маркетинг, Agile-менеджмент и маркетинг-

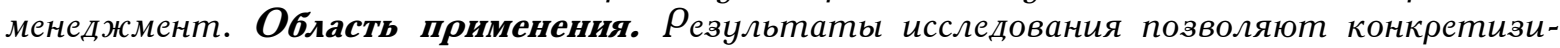
оовать направления совершенствования корпоративного маркетинга и менеджмента в современных условиях высокой неопределенности и сложностей привлечения инвестиционных ресурсов, могут быть использованы в качестве информационно-аналитического руководства при подготовке корпоративных и региональных программ развития. Выводы. Авторами делается заключение о возможности роста устойчивости функиионирования предприятий и региональных АПК на основе совершенствования корпоративного маркетинга и менеджмента.

Ключевые слова: маркетинг, менеджмент, устойчивость, Agile, регион, иифровизация агробизнеса.

SHEVTSOV VLADIMIR VIKTOROVICH

doctor of Economics, $\rho_{\text {rofessor Kuban state agrarian University }}$

University. I. T. Trubilina, Krasnodar, e-mail:denshevtsov0@ya.ru

KARPENKO GALINA GRIGORIEVNA

doctor of Economics, $P_{\text {rofessor Kuban state agrarian University }}$ University. I. T. Trubilina, Krasnodar, e-mail: denshevtsov0@ya.ru

\section{HACKING PRACTICES IN AGRIBUSINESS}

Abstract. The purpose of this article is based on the analysis of indicators of functioning of agroindustrial complex of Krasnodar region and one of the largest agricultural holdings of Russia -Agrocomplex "Vyselkovsky" and practice the effective use of modern marketing concepts and management to formulate the directions of improvement of marketing and management in modern Russian enterprises, the implementation of which can substantially increase the stability of the Russian agricultural complex in the conditions of confrontation through sanctions and import sub- 
stitution. The methodological basis of the work consists of the concepts of Agile marketing and management, marketing management, system, synergetic and prognostic approaches. The paper uses General theoretical (analysis, synthesis, analogy, comparison and comparison, generalization, typing) and General scientific methods. Results. The expediency of application of hacker practices in agribusiness arising from modern concepts of marketing and management, which are based on Agile marketing, Agile management and marketing management, is substantiated. Application. The results of the study allow to specify the directions of improvement of corporate marketing and management in modern conditions of high uncertainty and difficulties in attracting investment resources, can be used as information and analytical guidance in the preparation of corporate and regional development programs. Summary. The authors conclude that it is possible to increase the stability of the functioning of enterprises and regional agribusiness on the basis of improving corporate marketing and management.

Keywords: marketing, management, sustainability, Agile, region, digitalization of agribusiness.

В рамках менеджмента последних десятилетий пришло осознание того, что в нестандартных ситуациях менеджмент 1,0 работает недостаточно эффективно. В связи с этим были разработаны его расширения, такие как система сбалансированных показателей, шесть сигм, тотального управления качеством и др. Но и эти модели предполагают, что организации управляются сверху, а, следовательно, надо помогать в первую очередь топ-менеджерам в их стремлении повышать эффективность вертикали управления организаций.

Как известно, в современных условиях перманентных изменений в мировой экономике приоритетом является обеспечение миссии организации. Соответственно, корпоративное управление на основе гармоничного сочетания разнообразных управленческих стратегий и тактик должно стать гибким, а в стремительно происходящих трансформационных процессах и цифровизации традиционные подходы к менеджменту и маркетингу претерпевают серьезные изменения $[1,3,4]$.

В цифровом мире разработка современного программного обеспечения (далее - ПО) сходна со сложными задачами менеджмента и маркетинга. И то, и другое требует творческого и интеллектуального подхода, основу которого составляют предвидение и новые методы командной работы. Популярная методика, названная гибкой разработкой ПО, делала и делает упор на постоянные приращения, дублирования и увеличение числа укороченных циклов разработки при создании ПО. Это позволило в свое время существенно увеличить темпы его разработки, а сам процесс сделать проще и надежнее $[4,9]$.

Гибкая разработка ПО берет начало в 2001 году, когда группа основателей Agile (набор методов и методологий, мировоззрение) подготовила «Манифест гибкой разработки программного обеспечения», в котором они провозгласили приоритет ценности поставки работающего ПО вместо подготовки исчерпывающей документации, а также приоритет готовности к изменениям вместо следования первоначальному плану $[2,16]$.

Термин Agile имеет несколько значений: «способный двигаться быстро и легко», «связанный с чем-либо» или «обозначающий метод управления проектом, характеризующийся разделением задач на короткие этапы работы, частым пересмотром и адаптацией планов». Agile-манифест предполагает то, что реагирование на изменения важнее, чем следование первоначальному плану, а сотрудничество с заказчиком важнее согласования условий контракта $[1,14]$.

B Agile-манифесте высокую популярность получили методы управления Scrum, Kanban и Scrumban, как гибрид Scrum и Kanba, в которой особое внимание уделяется коротким итерациям, над которыми работает наделенная особыми полномочиями команда. Kanban считается методологией как бережливого, так и гибкого управления. У Agile-команд, как правило, плоская структура. В ее рамках никто не несет личной ответственности за каждого в команде, командные решения принимаются коллегиально, а приоритетным является распределенное лидерство [1, 14].

Прозрачность в Agile-командах помогает построить доверие в распределенной модели лидерства и показывает на необходимость компромисса. В таких командах все участники владеют одинаковой информацией и каждый член команды имеет свой голос при обсуждении раз- 
личных вопросов. Agile, как и Lean, стимулирует непрерывное улучшение процессов и практик, используемых командами. Такой фактор, как гибкость, позволяет маневрировать в условиях быстро меняющегося цифрового мира.

Мировоззрение Agile помогает членам команды делиться друг с другом информацией и самим принимать важные решения по проекту. Основными чертами современного Agileменеджмента следует считать гибкость (адаптация к изменениям через выборочность и эволюционные эксперименты), инновации, масштабируемость и человеческий ресурс $[1,9,16]$.

Суть Agile-маркетинга заключается в стимулировании большей заинтересованности в работе и ответственности за нее не только отдельных маркетологов и небольших маркетинговых команд, но и всех сотрудников организации на основе предоставления им необходимой свободы действий в достижении корпоративных целей. Agile-маркетинг подразумевает доверие и прозрачность, а не командно-административное управление [2, 4, 8].

Эффективным современным инструментом обеспечения устойчивого функционирования организаций является маркетинг-менеджмент, т. е. управленческая деятельность, связанная с осуществлением планирования, организации, координации, контроля, аудита, стимулирования всех подразделений отдела (управления) маркетинга предприятия. Основными положениями его являются: от маркетинга в отделе маркетинга - к маркетингу во всей организации; от организации по товарным единицам - к клиентоориентированной структуре компании; аутосорсинг и межфирменное взаимодействие; многообразие форм межфирменного взаимодействия: стратегические группы, альянсы, сетевые компании, партнерства; от ориентации на материальные активы - к накоплению нематериальных активов [7, 8, 21].

Таким образом, проникновение концепций управления из сферы ПО в менеджмент и маркетинг - это хороший пример «хакерства» в бизнес-среде. В среде разработчиков ПО слово «хакерство» обозначает не взлом, а умение сделать, изобрести что-то новое с помощью быстрых, разнообразных и интересных подходов в информационных технологиях.

Хакерство следует считать творческой силой, способной реализовать идею в обход существующих ограничений и в отношении маркетинга, и в отношении менеджмента. Дух хакерства: «все поддается улучшению, ничто не может быть совершенным» [2, 7]. В странах ОСЭР, например в США, Совет советников президента по науке и технике ежегодно представляют доклады о Программе NITRD (Networking and Information Technology Research and Development) по развитию возможностей информационных технологий (ИТ) [22, 23].

Таким образом, и опыт зарубежных стран свидетельствует о том, что корпорациям, в том числе и в сфере агробизнеса, необходимо внедрять методы управления, «выкованные» деятельностью разработчиков ПО, так как эффективными менеджмент и маркетинг могут быть лишь с применением цифровых технологий, поскольку им характерны скорость, адаптивность, сопредельность, точность и демократичность. Неиспользование этих надстроек, как показывает практика, в нынешних турбулентных условиях развития отечественной аграрной экономики не обеспечивает необходимого уровня устойчивости для региональных АПК и даже для высокотехнологичных предприятий агробизнеса [5, 6]. В этом можно убедиться в ходе анализа производственно-финансовой деятельности АПК Краснодарского края и одного из ведущих агрохолдингов России - АО фирма «Агрокомплекс "Выселковский"».

В январе-июне 2019 года в действующих ценах объем производства продукции сельского хозяйства всех сельскохозяйственных товаропроизводителей Краснодарского края в сопоставимой оценке к январю-июню 2018 года составил всего 102,4 процента. При этом оборот в действующих ценах увеличен в целом по АПК края лишь на 1,9 процента [11].

По состоянию на 1 июля 2019 года во всех категориях хозяйств Кубани насчитывалось 523,3 тыс. голов крупного рогатого скота. Это на 10,4 тыс. голов меньше уровня 2018 года. Это вызвано, в первую очередь, снижением поголовья КРС в сельхозпредприятиях края (далее - СХП). Сокращение поголовья коров произошло на 3,9 процента за счет СХП и на 0,4 процента личных подсобных хозяйств сельского населения (далее - ЛПХ) [11].

Устойчивое развитие свиноводства в крае осуществляется за счет строительства современных технологичных предприятий с высоким уровнем биологической защиты. На долю СХП приходится 96,5 процента всего поголовья свиней. На 1 июля 2019 года численность птицы в хозяйствах всех категорий составила 97,6 процента к соответствующему уровню 2018 года. 
ШЕВЦОВ В.В., КАРПЕНКО Г.Г.

ХАКЕРСКИЕ ПРАКТИКИ В АГРОБИЗНЕСЕ

ВСХП края оно снизилось на 5,2 процента $[5,6,11]$.

Производство молока за шесть месяцев 2019 года снизилось на 3,2 тыс. тонн и составило 99,6 процента к соответствующему уровню 2018 года. Основной объем молока, по данным статистики, был произведен в кубанских СХП - 65,9 процента, в ЛПХ - 26,1 и в крестьянских (фермерских) хозяйствах - 7,9 процентов (далее - К (Ф) Х). Производство яиц - на 7,0 млн штук меньше уровня 2018 года [11].

За пять месяцев 2019 года крупные и средние организации АПК Краснодарского края получили прибыль 13,7 млрд рублей, что ниже аналогичного периода 2018 года на 2,3 процента. Убыток по 111 убыточным предприятиям АПК края за январь-май 2019 года составил 4,9 млрд рублей. В целом по краевому АПК доля убыточных предприятий за январь-май 2019 года составила 29,3 процента от общего количества предприятий. Это больше соответствующего уровня 2018 года на 4,5 процентных пункта [11].

Таблица 1

Анализ показателей сокращенных бухгалтерских балансов АО фирма «Агрокомплекс» им. Н.И. Ткачева за 2014-2018 годы, млн руб.

\begin{tabular}{|c|c|c|c|c|c|c|}
\hline АКТИВ & 2014 год & 2015 год & 2016 год & 2017 год & 2018 год & $\begin{array}{c}\text { Темп роста } \\
2018 \text { к } \\
2014, \%\end{array}$ \\
\hline \multicolumn{7}{|l|}{ Внеоборотные активы } \\
\hline Основные средства & 21900218 & 28209322 & 35054388 & 36296877 & 35052036 & 160,1 \\
\hline Финансовые вложения & 3222768 & 1032888 & 36340169 & 57036302 & 57813914 & в17,9p. \\
\hline Итого по разделу I & 29999773 & 33327407 & 71394645 & 93333916 & 92866879 & в3,1p. \\
\hline \multicolumn{7}{|l|}{ Оборотные активы } \\
\hline Запасы & 11123489 & 14827705 & 15694052 & 15354664 & 14921678 & 134,1 \\
\hline Дебиторская задолженность & 8313522 & 15394918 & 11339406 & 7768135 & 6967962 & 83,8 \\
\hline Финансовые вложения & 983535 & 932875 & 231578 & 2267256 & 3579097 & в3,6p \\
\hline Денежные средства & 837896 & 5119542 & 737386 & 299497 & 412645 & 49,2 \\
\hline Прочие оборотные активы & 9777 & 21779 & 24325 & 41753 & 54639 & в5,6p. \\
\hline Итого по разделу II & 21268219 & 36296819 & 28026747 & 25731305 & 25936021 & 121,9 \\
\hline БАЛАНС & 51267992 & 69624226 & 99421392 & 119065221 & 118802900 & B2,3p. \\
\hline \multicolumn{7}{|l|}{ ПАССИВ } \\
\hline \multicolumn{7}{|l|}{ Капитал и резервы } \\
\hline $\begin{array}{l}\text { Нераспределенная прибыль } \\
\text { (непокрытый убыток) }\end{array}$ & 21318563 & 25644579 & 27682139 & 23900516 & 21739022 & 102,0 \\
\hline Итого по разделу III & 22531531 & 27549625 & 29696661 & 25875741 & 23708285 & 105,2 \\
\hline \multicolumn{7}{|l|}{ Долгосрочные обязательства } \\
\hline Заемные средства & 21616817 & 27380485 & 54103484 & 72238596 & 63558057 & в2,9p. \\
\hline Прочие обязательства & 3880 & 3087 & 536810 & 468718 & 783420 & 20191,2 \\
\hline Итого по разделу IV & 21620697 & 27383672 & 54640294 & 72707314 & 64341477 & B3,0p. \\
\hline \multicolumn{7}{|l|}{$\begin{array}{l}\text { Краткосрочные обязатель- } \\
\text { ства }\end{array}$} \\
\hline Заемные средства & 4533296 & 11549675 & 11958758 & 15601361 & 24136186 & в5,3p. \\
\hline Кредиторская задолженность & 2563206 & 2986662 & 2789697 & 4350778 & 6118070 & в $2,4 p$ \\
\hline Итого по разделу V & 7115764 & 14691029 & 15084437 & 20482166 & 30753138 & в4,3p. \\
\hline Баланс & 51267992 & 69624226 & 99421392 & 119065221 & 118802900 & в2,3p. \\
\hline
\end{tabular}

Источник: годовые отчеты АО фирма «Агрокомплекс» им. Н. И. Ткачева. 
Кредиторская задолженность на 1 июня 2019 года по предприятиям АПК Краснодарского края составила 105,7 млрд рублей. Дебиторская задолженность по СХП «Кубанина» 1 июня 2019 года составила 142,3 млрд рублей [11].

В среднем по крупным и средним предприятиям АПК края заработная плата составила 31,8 тыс. рублей, в том числе в сельском хозяйстве - 30,0 тыс. рублей [11].

Неустойчивый характер развития российского АПК во многом является следствием не соответствующих современным реалиям корпоративного маркетинга и менеджмента, о чем свидетельствует анализ открытой финансовой отчетности одного из крупнейших российских агрохолдингов - АО фирма «Агрокомплекс» имени Н. И. Ткачева Краснодарского края $[15,17$, $18]$.

В табл. 1 представлен анализ сокращенных бухгалтерских балансов АО фирма «Агрокомплекс» в динамике с 2014 по 2018 год. В силу определенных обстоятельств фирма имела возможность активно развиваться в последние годы. Из анализа сокращенных бухгалтерских балансов агрохолдинга следует, что в 2018 году по сравнению с 2014 годом фирма более чем в три раза увеличила стоимость своих внеоборотных активов. В то же время сумма оборотных активов относительно стабильна, объем нераспределенной прибыли за эти годы практически не изменился, а сумма долгосрочных и краткосрочных обязательств выросла более чем в четыре раза.

В связи с этим сумма обязательств агрофирмы на конец 2018 года составила более 167 тыс. рублей на каждый гектар пашни. Из ниже представленного графика динамики развития таких показателей, как валовая прибыль, проценты к уплате и чистая прибыль АО фирмы «Агрокомплекс» за 2015-2018 годы, следует, что на фоне существенного роста активов агрохолдинга за последние пять лет практически неизменным оставался размер валовой прибыли, а совокупные процентные выплаты «Агрокомплекса» по обязательствам только за 2017 и 2018 годы составили более 20 млрд рублей.

Вместо прибыли, которая была получена в 2014-2016 годы, в 2017 и 2018 годах агрофирма завершила свою хозяйственную деятельность с убытком. По итогам 2018 года убыток составил более 2,9 млрд руб., что, безусловно, вызвало негативную реакцию акционеров в отношении топ-менеджеров и совета директоров агрохолдинга.

Из данных табл. 2 «Динамика ликвидности бухгалтерского баланса АО фирма «Агрокомплекс» за 2014-2018 годы» видно, что ликвидность агрофирмы последние пять лет снижалась, а в последние три года исследуемого периода предприятие имеет неликвидный баланс.

Из анализа двух факторных моделей Альтмана и Федотовой (табл. 3) также следует, что за период с 2014 по 2018 год вероятность банкротства исследуемого агрохолдинга от «очень низкой» перешла в категорию «очень высокой».

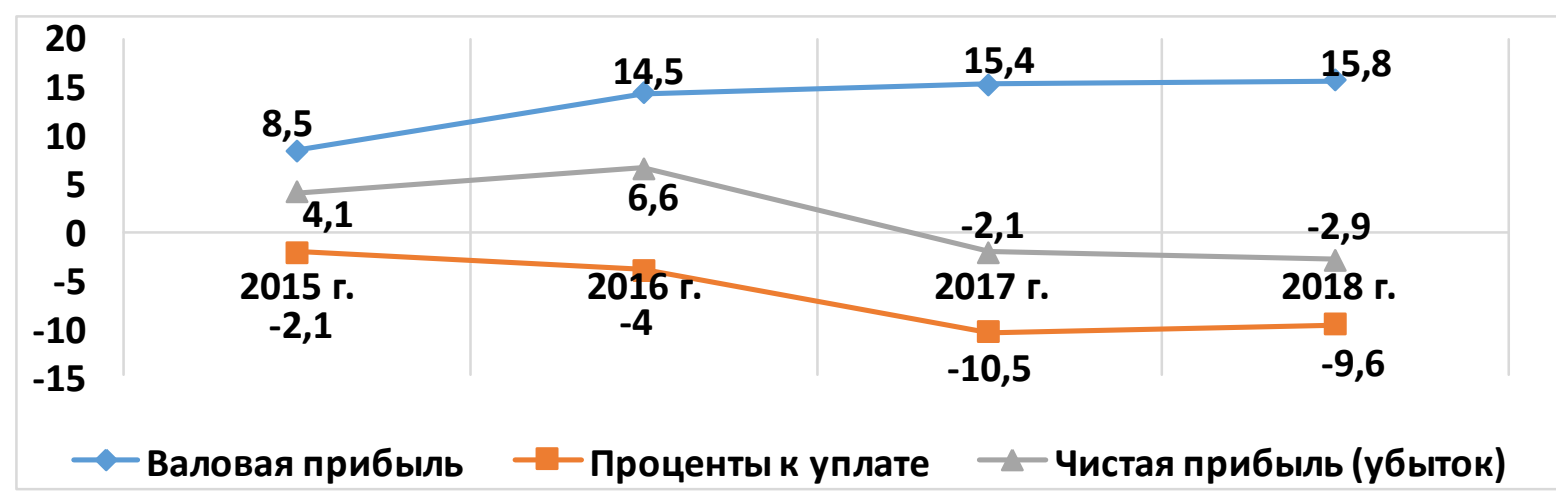

Источник: годовые отчеты АО фирма «Агрокомплекс» им. Н. И. Ткачева.

Pис. 1. Диналика показателей «валовая прибыль», «проиенты к уплате» и «чистая прибыль» АО фирма «Агрокомплекс» за 2015-2018 годы, млрд руб. 
ШеВцОВ В.В., КАРПЕНКо Г.Г.

ХАКЕРСКИЕ ПРАКТИКИ В АГРОБИЗНЕСЕ

Таблица 2

Динамика ликвидности бухгалтерского баланса АО фирма «Агрокомплекс» им. Н. И. Ткачева за 2014-2018 годы, млн руб.

\begin{tabular}{|c|c|c|c|c|c|}
\hline Активы/Пассивы & 2018 год & 2017 год & 2016 год & 2015 год & 2014 год \\
\hline А1 (Наиболее ликвидные активы) & 3991 & 2566 & 968 & 6052 & 1821 \\
\hline А2 (Быстро реализуемые активы) & 6967 & 7768 & 11339 & 15394 & 8313 \\
\hline А3 (Медленно реализуемые активы) & 14976 & 15396 & 15718 & 14849 & 11133 \\
\hline A4 (Трудно реализуемые активы) & 92866 & 93333 & 71394 & 33327 & 29999 \\
\hline П1 (Наиболее срочные обязательства) & 6118 & 4350 & 2789 & 2986 & 2563 \\
\hline П2 (Краткосрочные пассивы) & 24621 & 16117 & 12278 & 11686 & 4533 \\
\hline ПЗ (Долгосрочные пассивы) & 64341 & 72707 & 54640 & 27383 & 21620 \\
\hline П4 (Постоянные пассивы) & 23666 & 25848 & 29688 & 27545 & 22541 \\
\hline \multicolumn{6}{|l|}{ Условие } \\
\hline $\mathrm{A} 1 \geq \Pi 1$ & - & - & - & + & - \\
\hline $\mathrm{A} 2 \geq \Pi 2$ & - & - & - & + & + \\
\hline $\mathrm{A} 3 \geq \Pi 3$ & - & - & - & - & - \\
\hline $\mathrm{A} 4 \leq \Pi 4$ & - & - & - & - & - \\
\hline Анализ ликвидности баланса & $\begin{array}{l}\text { Баланс не } \\
\text { ликвиден }\end{array}$ & $\begin{array}{l}\text { Баланс не } \\
\text { ликвиден }\end{array}$ & $\begin{array}{l}\text { Баланс не } \\
\text { ликвиден }\end{array}$ & $\begin{array}{c}\text { Баланс } \\
\text { не ликвиден }\end{array}$ & $\begin{array}{c}\text { Баланс } \\
\text { не ликвиден }\end{array}$ \\
\hline
\end{tabular}

Примечание: + - выполняется условие, - - не выполняется условие неравенства.

Источник: годовые отчеты АО фирма «Агрокомплекс» им. Н. И. Ткачева.

Таблица 3 Определение вероятности банкротства по двухфакторной модели Альтмана
и Федотовой в АО фирма «Агрокомплекс» в 2014-2018 годах, млрд руб.

\begin{tabular}{|l|c|c|c|c|c|}
\hline \multicolumn{1}{|c|}{ Название модели } & $\mathbf{2 0 1 8}$ год & $\mathbf{2 0 1 7}$ год & $\mathbf{2 0 1 6}$ год & $\mathbf{2 0 1 5}$ год & $\mathbf{2 0 1 4}$ год \\
\hline Двухфакторная модель Альтмана & & & & & \\
\hline Х1 (текущие активы/текущие обязательства) & 0,843 & 1,256 & 1,858 & 2,471 & 2,989 \\
\hline Х2 (заемные средства/общая величина пассивов) & 0,259 & 0,172 & 0,152 & 0,211 & 0,139 \\
\hline Z (интегральный показатель) & $-1,278$ & $-1,726$ & $-2,374$ & $-3,028$ & $-3,589$ \\
\hline Вероятность банкротства, \% & $<50$ & $<50$ & $<50$ & $<50$ & $<50$ \\
\hline Двухфакторная модель Федотовой & & & & & \\
\hline Х1 (текущие активы/текущие обязательства) & 0,843 & 1,256 & 1,858 & 2,471 & 2,989 \\
\hline Х2 (коэффициент автономии) & 0,741 & 0,828 & 0,848 & 0,789 & 0,861 \\
\hline Z (интегральный показатель) & 1,393 & 1,593 & 1,772 & 1,869 & 2,081 \\
\hline Вероятность банкротства & $\begin{array}{c}\text { Очень вы- } \\
\text { сокая }\end{array}$ & $\begin{array}{c}\text { Очень вы- } \\
\text { сокая }\end{array}$ & $\begin{array}{c}\text { Очень вы- } \\
\text { сокая }\end{array}$ & $\begin{array}{c}\text { Очень вы- } \\
\text { сокая }\end{array}$ & $\begin{array}{c}\text { Очень } \\
\text { низкая }\end{array}$ \\
\hline
\end{tabular}

Источник: годовые отчеты АО фирма «Агрокомплекс» им. Н. И. Ткачева.

В силу особенностей учета в крупных и сверхсложных агропредприятиях некорректно делать категоричные и однозначные выводы. В то же время результаты формального анализа и явное «беспокойство» основных акционеров агрохолдинга дают основание предполагать о наличии серьезных недостатков в управлении даже достаточно «продвинутыми» агропредприятиями, вызванными, как нам представляется, недостаточным вниманием и к современным концепциям маркетинга и менеджмента, появившимся и зарекомендовавших себя в последние годы с положительной стороны $[12,13,19,20]$. 
По нашему мнению, заимствование концепций управления, возникших при разработке ПО, их адаптация к маркетингу и менеджменту следует воспринимать как естественный и перспективный источник вдохновения для современных организаций и в сфере аграрного бизнеса. В творческой адаптации этих концепций в сфере менеджмента и маркетинга как раз и будет проявляться хакерский дух, стимулирующий команды работать эффективнее на основе принятия оптимальных управленческих решений в организациях, где работники чувствуют себя счастливыми и испытывают неподдельную любовь к своей организации.

\section{Литература}

1. Agile-менеджмент: Лидерство и управление командами / Юрген Аппело; Пер. с англ. - М.: Альпина Паблишер, 2018. - 534 c.

2. Бринкер, Скотт. Agile-маркетинг. Хакерские практики для эффективного бизнеса / Скотт Бринкер; пер. с англ. И. Лейко [науч. ред. Ю. Тегель]. - М.: Манн, Иванов и Фербер, 2019. - 272 с.

3. Друкер П. Менеджмент. Вызовы ХХІ века. - М.: Манн, Иванов, Фербер.

4. Джеффри М. Маркетинг, основанный на данных. 15 ключевых показателей, которые должен знать каждый. - М.: Манн, Иванов и Фербер, 2013.

5. Карпенко Г. Г., Ярлыкапов А. Б. Государственное регулирование аграрного сектора экономики страны // Государственное управление. Электронный вестник. - 2011. - № 2. - C. 7-12.

6. Карпенко Г. Г. Ярльккапов А. Б. Совершенствование механизма государственного воздействия на аграрную экономику и оченка эффективности государственного регулирования АПК // Экономика и управление: проблемы, решения. - 2013. - № 12. - С. 3-13.

7. Комафорд, Коистин. SmartTribes. Как команды становятся успешными вместе / Кристиан Камофорд. пер. с англ. Е. Тортуновой. - Москва: Эксмо, 2015. - 272 с.

8. Котлер Ф. Маркетинг менеджмент. Экспресс-курс. 2-е изд. / Пер. с англ. под ред. С. Г. Божук. СПб.: Питер, 2006. - 464 с.

9. Кузес Джеймс М. Управляй как бог. Экстраординарный менеджмент в компании / Джеймс Кузес, Барри Познер/пер. с англ. В. С. Агеев. - Москва: Изд-во «Э», 2017. - 400 с.

10. Министерство сельского хозяйства РФ. [Электронный ресурс]. Режим доступа: http://mcx.ru/, свободный. - Загл. с экрана.

11. Министерство сельского хозяйства и перерабатывающей промышленности Краснодарского края. [Электронный ресурс]. Режим доступа: https://msh.krasnodar.ru/documents/, свободный. - Загл. с экрана.

12. Проблемы и перспективы развития АПК и сельских территорий / Бодрова Е. В., Бугара А. Н., Калинов В. В., Камбарова Е. А., СайфетдиновА. Р., Сайфетдинова Н. Р., Санникова А. Б., Смирнов П. А., Тюпаков К. Э., Шевиов В. В. - Новосибирск, 2015. - Т. 2.

13. Проблемы и перспективы развития АПК и сельских территорий / Аничкина О. А., Бериичкий Ю. И., Гайдаренко Л. В., Звонарева Л. В., Калитко С. А., Костенюкова Г. А., Маслюкова Е. А., Полушкина Т. М., Пиеничников В. В. „РябоваТ. Ф., Сайфетдинов А. Р., Сайфетдинова Н. Р., Смирнов М. П., Смирнов П. А., Сыромолотова Н. В., Текуева М. Т., Тюпаков К. Э., Шевичов В. В., Чернов С. С. - Новосибирск, 2017. - T. 3 .

14. Револющионный метод управления проектами / Джефф Сазерленд: Манн, Иванов и Фербер. Москва, 2016.

15. Совершенствование управления сельскохозяйственными предприятиями / Шевцов В. // Международный сельскохозяйственный журнал. - 2003. - № 6. - С. 20-23.

16. Современные педагогические и информационные технологии в системе образования / Докучаева И. В., Захарова Н. И., Захарова О. А., Карамзина А. Г., Коляго А. Л., Кормягина Н. Н., Магомедова Р. М., Макарова М. В., Михрютин В. В., Михрютина А. В., Назарова О. В., Сильнова С. В., Солдаткина Т. А., Шевцов В. В. Центр развития научного сотрудничества. - Новосибирск, 2013.

17. Шевцов В. Управление предприятием производственной инфраструктуры АПК // АПК: Экономика, управление. - 2000. - № 1. - С. 38-43.

18. Шевцов В. В. Производственная инфраструктура регионального АПК. - Краснодар, 2000.

19. Шевиов В. В. Микроэкономическая устойчивость и стратегическое предпринимательство. КубГАУ. - Краснодар, 2003.

20. Шевцов В. Микроэкономическая устойчивость сельскохозяйственных предприятий - стратегическая иель управления // Международный сельскохозяйственный журнал. - 2003. - № 4. - C. $21-24$.

21. Trade and Market in the Early Empires: Economies in History and Theory. Karl Polanyi, Conrad M. Arensberg, and Harry W. Pearson (editors). [An electronic resource]. Access mode: http://bookfi.net/ book/1391672, free. Heading from the screen.

22. Report to the President on Agricultural Preparedness and the Agriculture Research Enterprise. The President's Council of Advisors on Science and Technology. 2012.

23. Network research and development in the field of information technology. [An electronic resource]. Access mode: http://dir.md/, free. Heading from the screen.

\section{References:}

1. Agile-menedzhment: Liderstvo i upravlenie komandami / YUrgen Appelo; Per. s angl. - M.: Al'pina Pablisher, 2018. - $534 \mathrm{~s}$.

2. Brinker, Skott. Agile-marketing. Hakerskie praktiki dlya effektivnogo biznesa / Skott Brinker; per. s angl. I. 
ШЕВЦОВ В.В., КАРПЕНКО Г.Г.

ХАКЕРСКИЕ ПРАКТИКИ В АГРОБИЗНЕСЕ

Lejko [nauch. red. YU. Tegel']. - M.: Mann, Ivanov i Ferber, 2019. - 272 s.

3. Druker P. Menedzhment. Vyzovy XXI veka. - M.: Mann, Ivanov, Ferber.

4. Dzheffri M. Marketing, osnovannyj na dannyh. 15 klyuchevyh pokazatelej, kotorye dolzhen znat' kazhdyj. M.: Mann, Ivanov i Ferber, 2013.

5. Karpenko G. G., YArlykapov A. B. Gosudarstvennoe regulirovanie agrarnogo sektora ekonomiki strany // Gosudarstvennoe upravlenie. Elektronnyj vestnik. - 2011. - № 2. -S. 7-12.

6. Karpenko G. G. YArlykapov A. B. Sovershenstvovanie mekhanizma gosudarstvennogo vozdejstviya na agrarnuyu ekonomiku i ocenka effektivnosti gosudarstvennogo regulirovaniya APK // Ekonomika i upravlenie: problemy, resheniya. - 2013. - № 12. - S. 3-13.

7. Komaford, Koistin. SmartTribes. Kak komandy stanovyatsya uspeshnymi vmeste / Kristian Kamoford. per. s angl. E. Tortunovoj. - Moskva: Eksmo, 2015. - 272 s.

8. Kotler F. Marketing menedzhment. Ekspress-kurs. 2-e izd. / Per. s angl. pod red. S. G. Bozhuk. - SPb.: Piter, 2006. - 464 s.

9. Kuzes Dzhejms M. Upravlyaj kak bog. Ekstraordinarnyj menedzhment v kompanii / Dzhejms Kuzes, Barri Pozner/per. s angl. V. S. Ageev. - Moskva: Izd-vo «E», 2017. - 400 s.

10. Ministerstvo sel'skogo hozyajstva RF. [Elektronnyj resurs]. Rezhim dostupa: http://mcx.ru/, svobodnyj. Zagl. s ekrana.

11. Ministerstvo sel'skogo hozyajstva i pererabatyvayushchej promyshlennosti Krasnodarskogo kraya. [Elektronnyj resurs]. Rezhim dostupa: https://msh.krasnodar.ru/documents/, svobodnyj. - Zagl. s ekrana.

12. Problemy i perspektivy razvitiya APK i sel'skih territorij / Bodrova E. V., Bugara A. N., Kalinov V. V., Kambarova E. A., SajfetdinovA. R., Sajfetdinova N. R., Sannikova A. B., Smirnov P. A., Tyupakov K. E., SHevcov V. V. - Novosibirsk, 2015. - T. 2.

13. Problemy i perspektivy razvitiya APK i sel'skih territorij / Anichkina O. A., Bershickij YU. I., Gajdarenko L. V., Zvonareva L. V., Kalitko S. A., Kostenyukova G. A., Maslyukova E. A., Polushkina T. M., Pshenichnikov V. V., RyabovaT. F., Sajfetdinov A. R., Sajfetdinova N. R., Smirnov M. P., Smirnov P. A., Syromolotova N. V., Tekueva M. T., Tyupakov K. E., SHevcov V. V., CHernov S. S. - Novosibirsk, 2017. - T. 3.

14. Revolyucionnyj metod upravleniya proektami / Dzheff Sazerlend: Mann, Ivanov i Ferber. - Moskva, 2016.

15. Sovershenstvovanie upravleniya sel'skohozyajstvennymi predpriyatiyami / SHevcov V. // Mezhdunarodnyj sel'skohozyajstvennyj zhurnal. - 2003. - № 6. - S. 20-23.

16. Sovremennye pedagogicheskie $i$ informacionnye tekhnologii v sisteme obrazovaniya / Dokuchaeva I. V., Zaharova N. I., Zaharova O. A., Karamzina A. G., Kolyago A. L., Kormyagina N. N., Magomedova R. M., Makarova M. V., Mihryutin V.V., Mihryutina A. V., Nazarova O. V., Sil'nova S. V., Soldatkina T. A., SHevcov V. V. Centr razvitiya nauchnogo sotrudnichestva. - Novosibirsk, 2013.

17. SHevcov V. Upravlenie predpriyatiem proizvodstvennoj infrastruktury APK // APK: Ekonomika, upravlenie. - 2000. - № 1. - S. 38-43.

18. SHevcov V. V. Proizvodstvennaya infrastruktura regional'nogo APK. - Krasnodar, 2000.

19. SHevcov V. V. Mikroekonomicheskaya ustojchivost' i strategicheskoe predprinimatel'stvo. KubGAU. Krasnodar, 2003.

20. SHevcov V. Mikroekonomicheskaya ustojchivost' sel'skohozyajstvennyh predpriyatij-strategicheskaya cel' upravleniya // Mezhdunarodnyj sel'skohozyajstvennyj zhurnal. - 2003. - № 4. - S. 21-24.

21. Trade and Market in the Early Empires: Economies in History and Theory. Karl Polanyi, Conrad M. Arensberg,and Harry W. Pearson (editors). [An electronic resource]. Access mode: http://bookfi.net/ book/1391672, free. Heading from the screen.

22. Report to the President on Agricultural Preparedness and the Agriculture Research Enterprise. The President's Council of Advisors on Science and Technology. 2012.

23. Network research and development in the field of information technology. [An electronic resource]. Access mode: http://dir.md/, free. Heading from the screen. 